\title{
El motín del Asilo de Huérfanos. Reflexiones en torno a los sentidos y usos del trabajo. Ciudad de Buenos Aires, 1902
}

\author{
María Marta Aversa \\ Universidad de Buenos Aires, Argentina \\ maria.marta.aversa@gmail.com
}

\begin{abstract}
Resumen: El artículo analiza el motín desatado en el Asilo de Huérfanos de la ciudad de Buenos Aires en diciembre de 1902. La Sociedad de Beneficencia, administradora de dicho establecimiento, recopiló en ese momento las notas periodísticas y los sumarios e investigaciones abiertas por las autoridades. A través de este fondo documental se intentará reconstruir esa experiencia fugaz de lucha, teniendo como eje central el análisis, las experiencias laborales dentro y fuera del asilo, y las exceptivas y percepciones antagónicas en torno a los usos y sentidos del trabajo de los niños y jóvenes de las clases bajas
\end{abstract}

Palabras clave: infancia y juventud, pobreza, trabajo, tutela

Recibido: 31 de marzo de 2020. Aprobado: 8 de junio de 2020. 


\section{Introducción}

Los motines, como problema historiográfico, han estado enlazados a contextos de encierro o corrección (tales como cárceles), o con múltiples y complejos eventos de explosión popular en condados rurales o urbanos de las sociedades preindustriales. La expresión de ese descontento parece desbordar los canales de diálogo entre las autoridades y los sujetos populares, asociándose a episodios violentos que se agotan rápidamente en esas manifestaciones de furia frente a esquemas de poder vividos como injustos. Estas fugas nos acercan al fastidio y al enojo colectivo de personas humildes, quienes demuestran sus sentimientos o percepciones contrarias a sus jefes, gobernantes o patrones con expresiones que logran sacudir el orden cotidiano, y en ocasiones también el político.

En el caso presentado en esta investigación, el motín tuvo como lugar el Asilo de Huérfanos administrado por la Sociedad de Beneficencia de la ciudad de Buenos Aires, y sus protagonistas fueron jóvenes varones de entre 12 y 18 años que se encontraban en condición de asilados. Hasta ahora, el acceso al material documental clasificado de dicha Sociedad, ubicado en el Archivo General de la Nación, nos permite observar este episodio de explosión y lucha colectiva de estos niños y jóvenes, como el único caso vivido en la trayectoria institucional del lugar. Por eso considero significativo reconstruir este evento para poder, a partir de él, pensar qué conflictos o demandas sobre la cotidianidad del asilo fueron puestos en juego en dicha protesta.

Este acontecimiento ha sido mencionado en investigaciones y tesis recientes que desde el campo de la historia de la infancia y de la minoridad han examinado los debates políticos y las políticas que desde el Estado se desplegaron hacia un sector singular de la niñez. En este cuerpo de estudios se revela un complejo proceso de construcción social de los menores el cual, a partir de diversas intervenciones de múltiples actores (autoridades, intelectuales, policías, defensores de menores, administradoras de los asilos, y también las mismas familias pobres), terminó delineando senderos institucionales y comunitarios por donde circularon los niños y jóvenes (varones y mujeres) provenientes de las clases trabajadoras. Estas obras configuraron ese entramado cotidiano de la minoridad, logrando recomponer las experiencias y prácticas de los menores en contextos de encierro y corrección. ${ }^{1}$

1 Carla Villalta, Entregas y secuestros. El rol del estado en la apropiación de niños (Buenos Aires: CELS-Editores del Puerto, 2012); María Carolina Zapiola, Excluidos de la niñez. Menores, tutela estatal e instituciones de reforma. Buenos Aires, 
En este acontecer diario del asilo, con sus combates y disputas, será enmarcado el motín. En el contexto de la historia social, trataré de recalcar la relevancia de esta protesta como manifestación de problemas y tensiones propias de las relaciones de trabajo, desenvueltas en el espacio asilar: tanto entre los trabajadores (inspectores, celadores, maestros, encargados de los talleres) como entre los llamados “internos” (niños y jóvenes varones alojados por sus familias o por orden de los defensores de menores).

En esta perspectiva, el artículo trata de reconstruir la trascendencia de esta fugaz protesta que sacudió el devenir cotidiano del asilo demostrando la centralidad de las rutinas laborales en los talleres internos y en las demandas externas, y la notable permanencia de "muchachos" de 13 a 18 años, quienes podían entrar y salir del lugar para trabajar o estudiar. A partir de los legajos de la Sociedad de Beneficencia, se retomarán las crónicas periodísticas recolectadas en la época por las administradoras del Asilo y el sumario de investigación interno. De esta manera, esa furia colectiva desatada en una noche de diciembre de 1902 permite rastrear los diferentes usos y sentidos dados al trabajo, como eje organizador de la dinámica asilar. Asimismo, pone en escena numerosas voces, expectativas y valoraciones, expresadas en torno a las obligaciones y tareas impuestas a los menores en una relación tutelada (mediada por los defensores de menores y por las autoridades de los establecimientos de la Sociedad de Beneficencia). Por último, serán expuestas las consecuencias y repercusiones desatadas por el motín en la administración del Asilo de Huérfanos.

\section{Los circuitos de trabajo en el Asilo de Huérfanos}

En los establecimientos dirigidos por la Sociedad de Beneficencia, los varones y mujeres, infantes o jóvenes, que permanecían alojados bajo la figura de la tutela (tramitada por sus propias familias o impuesta por los defensores de menores), tuvieron que pasar gran parte del tiempo involucrados en la elaboración de los artículos empleados en los circuitos institucionales y en la práctica de oficios orientados a sostener las propias instalaciones. Según la edad y el género fueron organizadas diariamente un sinfín de tareas que posibilitaban el propio funcionamiento de las instituciones y la producción de

1890-1930 (Buenos Aires: Universidad Nacional de General Sarmiento, 2019); Claudia Freidenraij, La niñez desviada. La tutela estatal de niños pobres, huérfanos y delincuentes. Buenos Aires, 1890-1919 (Buenos Aires: Biblos, 2020). 
bienes o servicios ofrecidos a la comunidad y al Estado, que propiciaba la obtención de dinero.

La trama institucional de la minoridad dirigida hacia una infancia pobre, que esquivaba los límites de la escuela y el taller, comenzó a cobrar notoriedad desde fines del siglo XIX con la aparición de polémicas, debates y proyectos para crear instituciones correccionales modelo y marcos legales específicos. Ese proceso de configuración social de la minoridad en Argentina ha sido extraordinariamente analizado en los últimos años, por un conjunto de obras encuadradas en el campo de la historia de la infancia. Las tesis de posgrado de María Carolina Zapiola y Claudia Freidenraij, recientemente convertidas en libros, han ocupado un rol central en las definiciones sociales e históricas de los menores. Esa infancia excluida de los cuidados del hogar, de los juegos y de la formación educativa pobló las calles de Buenos Aires en búsqueda del sustento para ellos y sus humildes familias. Las autoridades y profesionales de esos años comenzaron a ligar ciertas formas de vida populares en los ámbitos urbanos, con nociones de delincuencia y peligrosidad social. La figura de la tutela pública ejercida por defensores y policías, y plasmada en las experiencias asilares, intentaba intervenir en esas trayectorias familiares golpeadas por el fenómeno de la pobreza material y moral. Entonces, la protección del Estado postulaba la necesidad de poner en marcha procedimientos e instituciones (asistenciales y penales), que pudieran garantizar la recuperación y regeneración de esas infancias y juventudes.

En la reconstrucción de estas historias se fueron perfilando las prácticas cotidianas de institucionalización en espacios tradicionales ligados a la caridad o en los nuevos establecimientos, tales como la Casa Correccional de menores o la Colonia de Marcos Paz. ${ }^{2}$ Estas observaciones permitieron reconocer la circulación de los menores (varones y mujeres) por diferentes tareas (educativas y laborales) puertas adentro del asilo, y en los alrededores de la vecindad. Pero esos múltiples roles estuvieron siempre encuadrados dentro de una relación tutelada, demarcada por los conceptos y fundamentos legales y jurídicos de la minoridad, como segmento singular de la administración estatal.

Partiendo de estas valiosas lecturas, intenté repensar esos circuitos de producción y formación gestionados por los asilos, como un intercambio

2 María Carolina Zapiola, Excluidos de la niñez; Claudia Freidenraij, La niñez desviada. Para el impacto de ese proceso de minoridad e institucionalización en zonas remotas de campaña bonaerense ver Yolanda Paz de Trueba, Infancia, pobreza y asistencia. Argentina, primera mitad del siglo XX (Rosario: Prohistoria, 2019). 
laboral que posibilitó, muchas veces, un ingreso temprano de los niños y niñas pobres a diversos mundos del trabajo en la ciudad de Buenos Aires. Desde esta perspectiva se pueden identificar múltiples colocaciones laborales en casas de familia, talleres, comercios, establecimientos rurales (en menor medida), y en dependencias estatales, tales como Batallones Militares o en los Territorios Nacionales. ${ }^{3}$

Las colocaciones se encontraban amparadas por las autoridades asilares encargadas de realizar las actas de colocación, por los defensores de menores que consignaban anualmente en sus informes el número de "menores" colocados junto a los destinos laborales y, fundamentalmente, por los vecinos de la ciudad habituados a buscar a estos niños o niñas como sirvientes, aprendices o simples criados.

De esta manera, el circuito de colocaciones nos pone frente a un denso y complejo campo de intercambios laborales en ámbitos domésticos, donde las exigencias de tareas se mezclaban con la vida cotidiana de la casa, y donde el mandato del patrón se desarrollaba bajo relaciones personales. Este ambiente de trabajo dependiente, en el cual el pago en dinero como retribución por la fuerza de trabajo fue una imposición sostenida y legitimada desde las defensorías, obliga a pensar las múltiples redes laborales en las que se insertaban los niños y niñas provenientes de las clases bajas en la ciudad de Buenos Aires.

El sistema de colocaciones resultó ser un mecanismo asentado en la propia dinámica cotidiana del patronato, ya que los asilos y las autoridades que los regentaban consignaban año tras año las salidas en calidad de colocados materializadas, no siempre, en la firma de un acta, en la cual las partes aclaraban sus cargas: el ciudadano con domicilio comprobado que retiraba a una niña o un niño se comprometía a criarlo, mantenerlo, formarlo en algún oficio, y a reconocer siempre la autoridad de las comisiones directivas del asilo con pleno derecho sobre el destino de sus asilados.

Aunque no se puede negar que para algunas personas este mecanismo de entrega de asilados pudo estar atravesado por vínculos afectivos y amorosos, en el trasfondo de las colocaciones, más allá de la integración al hogar familiar prevaleció, en la mayoría de los casos, el cumplimiento de tareas domésticas o productivas pocas veces remuneradas.

3 Sobre la dimensión del trabajo dentro y fuera de los asilos y la caracterización del trabajo infantil tutelado, ver María Marta Aversa, "Un mundo de gente menuda. El trabajo infantil tutelado, Ciudad de Buenos Aires 1870-1920" (Tesis de Doctorado, Facultad de Filosofía y Letras - UBA, 2014). 
En este sentido, muchos de los conflictos o problemas presentados en el marco de la tutela daban cuenta de ese frondoso campo de intervenciones de las autoridades, interposiciones de los vecinos, y en ocasiones acciones y peticiones de los chicos y chicas bajo el régimen de colocación. En estas confrontaciones de intereses quedaban plasmados diferentes roles jerárquicos de una relación centrada en el trabajo, que expresó expectativas encontradas entre las partes.

En las últimas décadas del siglo XIX, las experiencias de trabajo abiertas para los niños y muchachos comenzaron a ser percibidas como una preocupación esencial para políticos e intelectuales envueltos en la cuestión social, concentrados no solo en la identificación de los problemas compartidos por las clases bajas, sino también en la generación de políticas tendientes a encauzarlos.

La gravedad de la explotación laboral infantil respaldó las demandas por un mayor control y regulación del Estado. En los primeros años del siglo XX, las militantes socialistas Gabriela L. de Coni y Carolina Muzzilli, dedicadas a la defensa de la familia obrera, iniciaron las inspecciones del gobierno municipal en los talleres de la ciudad. En 1904, Joaquín V. González, por ese entonces Ministro del Interior, encargó la realización de un balance sobre las condiciones de trabajo verificadas en el interior del país. El informe "Estado de las clases obreras argentinas a comienzo de siglo" redactado y publicado por Juan Bialet Massé, fue divulgado en los boletines del Departamento Nacional del Trabajo entre 1911 y 1919, aportando referencias sobre el trabajo infantil en las zonas rurales. En ese mismo año, el ministro Joaquín V. González elevaba al Congreso un proyecto de reglamentación del trabajo de niños, que establecía jornadas variables según las edades y los tipos de ocupación en las distintas regiones del país. ${ }^{*}$

La preocupación por las implicancias del trabajo en mujeres y niños se encuadraba en una fundamentación biológica y natural que impedía la realización de ciertas tareas. Esta "debilidad física", expuesta en las trayectorias laborales de mujeres, niños y niñas, determinaba la imperiosa intervención del Estado prohibiendo los oficios malsanos y peligrosos, y reglamentando las tareas posibles de ser ejercidas. En el mes de junio de 1906, el diputado socialista Alfredo Palacios presentaba su proyecto basado en los informes previos de Gabriela L de Coni. Luego de ser debatido, fue

4 Joaquín V. González, "Mensaje relacionado con el trabajo de niños al Honorable Congreso de la Nación del 6 de mayo de 1904", en Protección a la infancia: antecedentes para el estudio de una ley (Buenos Aires: Patronato de la Infancia, 1908) 107. 
aprobado en 1907 como la Ley 5291 de "Trabajo de mujeres y menores", reglamentada solo para la Capital Federal y los territorios nacionales. Esta legislación estableció que no podían ser contratados los menores de 10 años ni los mayores que no hubieran completado la instrucción obligatoria. Prohibía los trabajos nocturnos a menores de 16 años, los dañinos para su salud, formación o moralidad, y establecía en Capital una jornada máxima de 8 horas y la prohibición del empleo de menores de 12 años en la industria. En estas nuevas normativas quedó plasmada la autoridad de los defensores de menores en el registro e inspección de las contrataciones de los niños y niñas trabajadoras en las diversas ramas del mercado de trabajo porteño.

En paralelo a los dilemas y los marcos legales abiertos por el trabajo infantil, se fueron delineando, también, diagnósticos y conceptos morales que estigmatizaron ciertas prácticas laborales como insanas y lindantes con el delito (oficios callejeros), y proclamaron otras como fuentes de virtudes (ocupaciones en talleres, comercios o establecimientos rurales).

Al margen de estas apreciaciones, se daban las estrategias de las familias populares que involucraron a sus hijos e hijas en la búsqueda del sustento diario. La relevancia de la contribución de estos pequeños trabajadores como productores, vendedores y proveedores de servicios se perdía en la cotidianidad de sus actividades y en la aceptación de sus comunidades. Recientes investigaciones han rescatado la agencia histórica y la función económica de niños y jóvenes en las dinámicas productivas. Ludmila Scheinkman ha historizado las experiencias de trabajo y protesta entre los trabajadores y trabajadoras mayores y menores en las fábricas de dulces en Barracas y sus alrededores para los primeros años del siglo XX. Contrariamente a los ideales de protección expresados en los debates de la época, la contratación por parte de empresarios y la colocación de niños y niñas por parte de las mismas familias era un fenómeno extendido en distintos talleres y comercios de la ciudad. Para tareas que demandaban abundante mano de obra, pericia y sistematicidad, pero escaso conocimiento técnico, desde finales del siglo XIX se empleaban infantes y mujeres. En ocasiones, las dos Defensorías de menores (sección norte y sur) ubicaban en las usinas a los pequeños "abandonados y delincuentes" bajo su tutela, en condiciones que orillaban los límites del trabajo asalariado "libre" o "no libre".

5 Para el caso argentino ver Ludmila Scheinkman, "Trabajo femenino, masculino e infantil en la industria del dulce porteña en la primera mitad del siglo XX. Experiencias laborales, protesta y vida cotidiana" (Tesis de Doctorado, Facultad de Filosofía y Letras - UBA, 2017). Para un análisis del rol económico de la 
Por eso, la presencia constante de estos pequeños y pequeñas en fluctuantes oficios y tareas evidencian una actuación significativa en la producción e intercambio de bienes y servicios para sus familias o para su propio sustento. En este marco, los destinos laborales del sistema de colocación comenzaban a ser considerados por las autoridades, especialmente los defensores de menores, en función de las nociones de regeneración fundamentadas por los intelectuales y profesionales, quienes comenzaban a ocupar funciones en las emergentes instituciones de menores. Las oportunidades de trabajo que se presentaban en la ciudad fueron juzgadas por sus implicancias "económicas y morales": para la infancia popular el empleo debía posibilitar un ingreso salarial pero además una formación integral que combinara conocimientos técnicos y virtudes cívicas.

En el año 1902, J. M. Terrero, defensor de menores de la sección sur, presentaba en su informe anual -comprendido en las Memorias del Ministerio de Justicia, Instrucción Pública y Culto- los números de ingresos y de las colocaciones en casas particulares y en otros establecimientos: 520 menores (152 varones y 377 mujeres) estaban bajo relación tutelar, 474 fueron colocados en casas particulares y 12 enviados al Ejercito Nacional. ${ }^{6}$ Por su parte, Pedro de Elizalde, defensor de la sección norte, mostraba el ingreso de 510 menores (182 varones y 328 mujeres) y la entrega a casas particulares de 168 menores, de 10 a bandas militares y 7 puestos en el acorazado Almirante Brown.

La estadística anual de las colocaciones, o de entradas y salidas para utilizar las categorías de estos funcionarios, dejaba en evidencia la notoria extensión de las entregas a casas particulares o familias, que solicitaban un "huérfano" o “expósito” para integrarlo a la vida doméstica como sirviente o criado.

Las trayectorias abiertas por las colocaciones parecían estar asentadas en las costumbres comunitarias y en la aceptación de imponer cargas y trabajos a los hijos e hijas de los pobres a cambio de una "endeble" promesa de alimentarlos y educarlos. El defensor de la sección norte, Ramón de O. Cezar, impuso que los "menores fueran presentados en su oficina cuando menos dos veces al año, con el fin de examinar si se llenan las condiciones

infancia en México: Susana Sosenski, Niños en acción. El trabajo infantil en la ciudad de México, 1920-1934 (México: El Colegio de México, 2010).

6 "Informe del Defensor de Menores de la sección norte y de la sección sur", en Memorias del Ministerio de Justicia, Culto e Instrucción Pública (Buenos Aires: Ministerio de Justicia, Culto e Instrucción Pública, 1902), 107-117. 
convenientes”. ${ }^{7}$ Dos años más tarde, en 1892, el defensor de la sección sur, E. Rojas, con el fin de mejorar los trámites de entregas exigió “a las personas que hayan solicitado un menor y no han merecido confianza dos cartas de recomendación de personas honorables" que garanticen el buen trato de los menores. $^{8}$

En este clima crítico al circuito de colocaciones y desplazamientos domésticos, los defensores no solo lucharon por imponer medidas para un mejor control, como fueron las firmas de actas y contratos, la fijación de un pago económico o peculio, y los nuevos requisitos para los vecinos. También en sus memorias anuales se plasmaba una clara reprobación al servicio doméstico como un ámbito de explotación lindante a la servidumbre: "los infelices menores, han sido, frecuentemente abusados, por su mala alimentación en que se les ha tenido, agregando a esto el trato más cruel”. ${ }^{9}$

El seguimiento de las rutinas administrativas permite el rastreo de las variadas apreciaciones en torno al trabajo y los destinos laborales de los “menores", encuadrados en una relación tutelar. En ese vasto panorama, todos los actores naturalizaron el temprano ingreso de la infancia pobre al mundo del trabajo, y la asociación de la instrucción con el fomento y adquisición de oficios, delineados en términos de clase y género, que posibilitarían la preparación de las niñas como futuras costureras o sirvientas y de los niños como zapateros o herreros. ${ }^{10}$

A principios del siglo XX se desató una polémica entre las mujeres integrantes de la Comisión Directiva de la Sociedad de Beneficencia y el rector del asilo, el Presbítero Bernabé Pedernera. En el año 1902 afloraron choques y malentendidos, fundamentalmente en torno al funcionamiento de algunos talleres productivos.

En el Asilo de Huérfanos las rutinas impuestas se encontraban centradas en tareas domésticas y en el aprendizaje de oficios, en los cuales la formación se

7 Memorias del Ministerio de Justicia, Culto e Instrucción Pública (Buenos Aires: Ministerio de Justicia, Culto e Instrucción Pública, 1890), 148.

8 Memorias del Ministerio de Justicia, Culto e Instrucción Pública. (Buenos Aires: Ministerio de Justicia, Culto e Instrucción Pública, 1892), 164.

9 Memorias del Ministerio de Justicia, Culto e Instrucción Pública (Buenos Aires: Ministerio de Justicia, Culto e Instrucción Pública, 1894), 146.

10 En Argentina las actas de colocación no implicaron un traspaso de la tutela a los ciudadanos particulares, como sí se puede ver en otros contextos latinoamericanos como México y Chile. Ann S. Blum, Domestic economies. Family, work and welfare in Mexico City, 1884-1943 (Lincoln: University of Nebraska Press, 2009) y Nara Milanich, Children offate. Childhood, class and the state in Chile, 1850-1930 (Durham: Duke University Press, 2009). 
lograba fusionar con la elaboración de productos o servicios comerciados en la comunidad y en dependencias del Estado por medio de licitaciones. La búsqueda de esas tramas cotidianas nos posibilita observar las experiencias centrales del trabajo, pero sobre todo las desavenencias en torno a los usos y tipos de tareas laborales que trascendieron los muros del asilo.

\section{La vida en el asilo de Huérfanos}

En las décadas de 1870 y 1880, los enfrentamientos armados (Guerra del Paraguay) y los brotes de epidemias provocaron un aumento considerable del número de asilados y asiladas, que obligaron a replantear la capacidad de los establecimientos asilares y las nociones de "abandono y orfandad" en la ciudad. En este contexto, el Asilo de Huérfanos comenzó a ser construido en 1871 bajo la presidencia de Domingo F. Sarmiento, en una manzana del barrio de Balvanera comprendida por las calles Saavedra y México y las avenidas Independencia y Jujuy. La dirección económica y administrativa quedaba en manos de la Sociedad de Beneficencia por decreto presidencial del 21 de noviembre de 1972, porque las infancias necesitaban para su bienestar del "esmerado y afectuoso cuidado que sólo puede prestar la mujer educada". ${ }^{11}$

En un comienzo, el lugar albergaba a niñas y niños ubicados en secciones diferenciadas a partir de los 10 años. A raíz del motín de diciembre de 1902, se llevó a cabo una reforma del reglamento asilar que reorientó el lugar exclusivamente para varones de 10 a 18 años. El nuevo reglamento transformado en 1903 ordenó la población de niños y jóvenes en dos departamentos: el primero para aquellos de 6 a 10 años y el segundo para los de 10 a 15 años. La organización del tiempo estaba reglamentariamente precisada: desde que se levantaban hasta que se acostaban por las noches cada actividad tenía marcada su extensión y se anunciaba por toque de campana a cargo de un empleado de cada departamento. Los niños y jóvenes tenían media hora para almorzar, momentos de descanso o recreación, tareas de limpieza, las clases educativas y el trabajo en los talleres. ${ }^{12}$

Algunas de las ocupaciones desarrolladas dentro y fuera del asilo tuvieron un pago de dinero (peculio) depositado en el Banco de la Nación. Aquellos que participaban de un solo taller, después de un año podían recibir un pequeño sueldo determinado por el rector, de acuerdo con el jefe de talleres, "según

\footnotetext{
11 Archivo General de la Nación (AGN), Fondo Documental de la Sociedad de Beneficencia (FDSB), Sala VII, Correspondencia 1855- 1909, folio 71.

12 AGN, FDSB, Sala VII, Correspondencia 1901-1909, f. 267.
} 
las aptitudes, conducta y aplicación del interesado". Los saldos de dinero eran depositados en el banco para ser entregados al egreso con autorización de las autoridades asilares o de los defensores de menores. Los chicos que se daban a la fuga o eran expulsados perdían las posibilidades de cobrar y los depósitos eran transferidos a la Caja del asilo. ${ }^{13}$

Este tipo de imposiciones realza la centralidad de las jornadas laborales para mantener en funcionamiento los engranajes del establecimiento. Las clases consistían en horas dedicadas al aprendizaje de contenidos básicos (lengua, aritmética, historia) y a las tareas requeridas en los talleres, espacios que combinaban la formación de oficios, la provisión de bienes y servicios para los internos y la comercialización entre los vecinos de los alrededores. En este sentido, todos aquellos que generaban limitaciones en este proceso de entrenamiento y producción por diferentes problemas de salud debían ser rechazados. Además, se estipulaba que los alumnos fugados, una vez capturados, tenían terminantemente prohibido la entrada nuevamente al lugar. ${ }^{14}$

La búsqueda de las tramas cotidianas en que se desenvolvieron estos chicos ha posibilitado reconocer la centralidad del trabajo y del entrenamiento laboral, tanto para el mantenimiento y funcionamiento de la red asilar como para el fomento de la regeneración moral de sus poblaciones. La formación que se impartía en los asilos abarcaba actividades consideradas productivas porque podían generar ingresos y tareas valoradas como domésticas, porque facilitaban la reproducción de la vida diaria. Ambas trayectorias laborales fueron vitales para el sostenimiento de los establecimientos públicos. Pero sobre ellas los directivos, celadores y maestros de los talleres manifestaban diferentes y contrapuestos sentidos sobre los usos y jerarquías del trabajo. De esta manera, algunas ocupaciones podían ser productivas y generar la preparación en oficios demandados en el mercado de trabajo. En tanto, las faenas de limpieza estaban asociadas al propio orden asilar y al régimen disciplinario que debían mantener los internos. En el fondo, repercutían entre los actores nociones morales y utilitarias en torno al trabajo en un contexto de tutela.

13 El 22 de agosto de 1898, el rector del Asilo de Huérfanos, Bernabé E.

Pedernera, escribía a la señora presidenta de la Sociedad de Beneficencia una carta comunicando la fuga del "menor Bonifacio García” y rogando la orden de retirar del banco "los depósitos hechos por esta dirección a nombre del menor aludido cuyas remesas de dinero fueron: la primera remitida el 17 de enero por valor de 49,75 pesos y la segunda el 28 de mayo por valor de 24 pesos". AGN, FDSB, sala VII, Correspondencia 1855-1901, f. 70.

14 AGN, FDSB, Sala VII, Correspondencia 1901-1909, f. 263. 
En los primeros años del siglo XX, las transformaciones políticas y económicas colocaban a Argentina entre las naciones más modernas entre los países latinoamericanos. La economía agroexportadora significó una incorporación desigual de las diferentes regiones y de las clases sociales que en esos primeros años configuraron conflictos por el trabajo, los derechos y las condiciones de vida. Las protestas obreras y las manifestaciones concretas del avance del pauperismo cobraban visibilidad en el paisaje urbano y en la agenda de intelectuales y políticos. ${ }^{15}$ Frente a las novedosas formas de conflictividad social, la intranquilidad de los sectores política e intelectualmente dirigentes comenzó a expresarse en proyectos legislativos y acciones políticas que redefinieron el alcance del Estado sobre las relaciones familiares y domésticas de las clases bajas. Desde 1892, el Congreso argentino recibió peticiones para la sanción de una ley que avanzara en las capacidades de intervención del Estado sobre los adultos considerados incapaces de garantizar la crianza de sus hijos e hijas. ${ }^{16}$ En 1910, el diputado Luis Agote presentó al Congreso su propuesta sobre el Patronato, que debió ser expuesta en cuatro oportunidades: tuvieron que hacerse dieciocho mociones de preferencia para que sea estudiada, tratada y finalmente aprobada por la Cámara en 1919.

Ahora bien, en el clima cotidiano del asilo, los ideales de tutela material y moral se contraponían con las limitaciones presupuestarias y con las múltiples expectativas de los actores. Lejos de los despachos de los funcionarios, el día a día de la dinámica asilar estaba asentado sobre una estructurada rutina de actividades formadoras, productivas y domésticas de los "internos".

En 1902, la Sociedad de Beneficencia, en el marco de sus bodas de oro en la administración del Asilo de Huérfanos, decidió encarar una profunda reorganización de sus espacios de trabajo y de educación. Para dicho

15 Huelgas, boicots y manifestaciones fueron las formas de protesta más utilizadas para visibilizar el descontento obrero. En estos años se produjeron numerosas huelgas parciales y generales. Algunas fueron masivas como en 1902, $1907 \mathrm{y}$ 1909, otras fragmentadas como en 1905, 1908 y 1919. Desde que se convocó la primera huelga general en 1902, el Estado reforzó su política represiva a partir de la Ley de Residencia y de los estados de sitio decretados.

16 En 1892, el Patronato de la Infancia, apoyado por personajes influyentes de la época, presentó el primer reclamo para la sanción de una ley para la infancia “desvalida”. En 1896, el legislador Antonio V. Obligado presentaba un nuevo proyecto para la protección de la infancia, respaldado por el Patronato de la Infancia. 
propósito fue conformada una comisión especial integrada por Rómulo Ayerza, el ingeniero Arteaga y el presbítero Gabriel Desbarats.

En ese momento, el director del asilo, desde hacía 12 años, era el padre Bernabé Pedernera. Su obra, volcada en fortalecer los talleres de trabajo y, por ende, desarrollar oportunidades de empleo para los internos, se fue asentando durante su administración. En los legajos del Asilo de Huérfanos (desde fines del siglo XIX hasta principios del XX) encontramos notas y pedidos elevados por el presbítero Pedernera a las encargadas de la Sociedad, en los cuales informaba el funcionamiento de los talleres o solicitaba los pagos de menores o ex alumnos. ${ }^{17}$

De hecho, en el mes de junio su tarea fue reconocida por la prensa porteña cuando el diario El Pueblo editó una nota periodística con el título "Los talleres del Asilo de Huérfanos. Una iniciativa progresista y fecunda”. En ella Pedernera contaba cómo había sido la difícil tarea de llevar adelante la ampliación y consolidación de los talleres. Con el permiso de la Comisión Directiva y con "el apoyo moral de algunos amigos e industriales, se fueron agrupando distintas secciones". De esta manera, el "humilde rincón de proyecto de carpintería" logró convertirse en una "regular agrupación de talleres, donde puede verse trabajar más de 80 alumnos en las secciones de tipografía, galvanoplastía, electricidad, herrería y mecánica”. ${ }^{18}$

Según sus palabras, los talleres contaban con una "buena clientela que permitía costear gratuitamente la enseñanza industrial de los alumnos". Compartió con la prensa "los balances comprobatorios de los movimientos de cada taller" para demostrar la importancia de este entrenamiento y aprendizaje. Con las estadísticas pretendía legitimar y justificar la sección de los talleres frente a los muchos críticos de "inteligencias pobres", que cuestionaban su rentabilidad económica: "de los talleres donde se forman los futuros operarios, saldrán los hombres, que cual poderosas columnas sabrán sostener firmes la libertad, el progreso y la integridad de nuestra querida patria". ${ }^{19}$

17 El 19 de octubre de 1901, Bernabé Pedernera solicitaba el cobro de los depósitos del portador de la carta: "Marcelino Carranza, ex alumno de este establecimiento, es el dueño de los fondos depositados, bajo ese nombre en el Banco de La Nación, cuya libreta debe estar en poder de la Oficina Directiva de la Sociedad. La cantidad que este establecimiento ha depositado a ese nombre, suma doscientos veinte y seis pesos”. AGN, FDSB, Sala VII, Asilo de Huérfanos 1901-1909, legajo 93, f. 42.

18 AGN, FDSB, Sala VII, Recortes Diarios, El Pueblo, 2 de junio de 1902.

19 Ibídem. 
En los entredichos que eventualmente surgían entre las socias de la Sociedad, los encargados de los asilos y los maestros de los talleres, éstos últimos, responsables del entrenamiento y producción, se veían obligados a demostrar la autosuficiencia de esos espacios probando que lograban producir para las necesidades internas del asilo y para las demandas de vecinos. ${ }^{20}$ En 1902, el Asilo parecía estar atravesando ese tipo de altercado en el cual los administradores, con sus ideales de moralización, y los trabajadores, con sus propias necesidades, disputaban y redefinían los usos y sentidos de la formación educativa y laboral.

En ese mismo año, otra de las secciones que desató la polémica, también plasmada en las páginas de los diarios, fue la del Batallón Maipú o Maipo. Según la investigación de Diego Conte, el Batallón fue creado en 1874 (tres años después de la inauguración del Asilo) por iniciativa de las propias inspectoras "Jacinta Castro, Adela Blaye Peña y Dolores Lavalle de Lavalle, en respuesta a las condiciones físicas de los huérfanos de aspecto raquítico y endeble, como consecuencia de una epidemia interna de oftalmia purulenta”. ${ }^{21}$ En sus inicios fue constituido como una banda de músicos que animaban fiestas y fechas conmemorativas bajo el marco de la instrucción militar. Con la instauración de la capital de la República en Buenos Aires, la organización del Batallón cambió de rumbo con el establecimiento de la enseñanza de ejercicios militares, desde enero de 1883. El nuevo perfil suministraba un ordenamiento jerárquico y de mando militar, similar al que tenía el Ejército.

El disciplinamiento y la formación militar tuvieron desde los últimos años del siglo XIX un notable crédito entre autoridades y profesionales. Las clases militares se veían como prácticas propicias para modelar física y moralmente a los "internos", pero también podían brindar una formación laboral y una futura carrera en el Ejército.

A finales del año 1900, el Ministerio de Guerra anunciaba la finalización del envío de carabinas con los machetes y correajes correspondientes, utilizados en los entrenamientos y desfiles. La Comisión Directiva de la Sociedad comenzó a pensar en la posible disolución definitiva del Batallón, que ya no iba a contar con los recursos provistos por el gobierno nacional.

En 1901, en pleno estado de sitio por el conflictivo clima social y de huelgas obreras, Pedernera prestó al comisario de la seccional $8^{\circ}$ un importante

20 Aversa, El trabajo infantil tutelado, 178-241.

21 Diego Conte, "Los niños militares del Asilo de Huérfanos: organización y disolución del Batallón Maipú, ciudad de Buenos Aires (1871-1902)”, en Horizontes y convergencias. Lecturas históricas y antropológicas del derecho, 2001. 
número de fusiles sin consultas ni autorización de la Comisión Directiva de la Sociedad. Desde ese momento, una sucesión de hechos terminó por distanciar definitivamente el interés de Pedernera del de las mujeres integrantes de la asociación. ${ }^{22}$

A pesar del tenso clima, aprovechando la conmemoración del $92^{\circ}$ aniversario del 25 de Mayo y la participación de los "pequeños soldados" en los actos y desfiles, el capellán Pedernera le solicitó a la presidenta de la Sociedad la designación de los integrantes del Batallón. En respuesta, las inspectoras presentaron el día 24 de mayo de 1902 los nombramientos correspondientes de los asilados, los cuales recaían, "dada sus condiciones de competencia, disciplina y moralidad en los siguientes alumnos: Coronel de Infantería. Dardo V. Gómez. Coronel. Carlos E. Figini. Mayor Ayudante. Isidoro Cur. (...)". ${ }^{23}$ Entre los jóvenes promovidos a los grados equivalentes al Ejército figuraron varios nombres de los futuros "cabecillas" del motín. El coronel Dardo V. Gómez, en particular, aparecerá denunciado como el principal promotor de los disturbios en el sumario oficial de la Sociedad.

En el mes de septiembre, los "Batallones Infantiles", como los mencionaba la prensa, desfilaron por la Avenida de Mayo, siendo "una de las notas más simpáticas de los festejos" del aniversario de la Sociedad. ${ }^{24}$ Pero las mujeres de la Comisión Directiva seguían interesadas en reorganizar el funcionamiento de talleres y descartar otras actividades, tales como las clases militares. Frente a esto, el padre Pedernera intentó defender los beneficios económicos de los talleres cuestionados y del Batallón difundiendo sus opiniones en la prensa porteña.

Si bien ambos bandos defendían el trabajo como un mecanismo óptimo de reencauzamiento de los hijos e hijas de las familias pobres, esa conveniencia aportada por las obligaciones laborales iba cobrando diferentes sentidos. El rector Pedernera defendía los talleres y al Batallón porque permitían la formación y la generación de recursos. En tanto, la Comisión Directiva creyó conveniente observar las condiciones educativas y laborales priorizando las actividades que fueran útiles y funcionales al auto sostenimiento de los asilos.

El trabajo enmarcado en la tutela planteaba el problema de para qué y para quiénes se destinaban las ganancias, los servicios y los productos elaborados por los niños y jóvenes asilados. Esta rígida atmosfera aparece representada en los informes de las autoridades asilares y en las apreciaciones hechas por

22 Diego Conte, "Los niños militares".

23 AGN, FDSB, Sala VII, Asilo de Huérfanos 1901-1909, legajo 93, f. 91.

24 AGN, FDSB, Sala VII, Recortes Diarios, El Pueblo, 10 de septiembre de 1902. 
la prensa. El trabajo y la disciplina se manifestaron como problemas que en el mes de diciembre de 1902 desbordaron los despachos y las facultades de los directivos y empleados para estallar en gritos y destrozos de un grupo de jóvenes que vieron peligrar sus estudios y ocupaciones.

\section{El motín: la revuelta de "menores” estudiantes y trabajadores}

El 17 de diciembre de 1902, a las nueve de la noche, cuando las luces de los dormitorios estaban apagadas y los asilados acostados en sus camas, se produjo un repentino apagón en los corredores y pasillos. Un guardián sorprendido pensó que sería una travesura de algún chico, pero enseguida comenzaron a oírse los gritos. Un grupo de jóvenes atacó el registro eléctrico y “haciendo sonar el clarín del regimiento lanzó el llamado de jal ataque!”. En ese instante, "un barullo infernal" invadió el lugar: ruidos de armas, vidrios que se rompían, bancos y otros objetos que chocaban contra puertas y ventanas, "y por sobre todo el clarín del batalloncito tocando furiosamente ¡fuego! fuego!". ${ }^{25}$ Cuando llegaron a la pieza del vicerrector "fue Troya": la santa Biblia, las meditaciones de San Lucas y todos los ejemplares teológicos guardados en la biblioteca fueron destruidos a bayoneta limpia y desparramados en el piso. Mientras unos atacaban una sala y otros el comedor, las piezas de los guardianes o tomaban rumbo a la calle, las puertas habían sido abiertas de par en par. Cuando llegaron las fuerzas de la policía el clarín ya mandaba a cesar el fuego pero los combatientes entusiasmados no le hacían caso.

Según el cronista de El Diario, los vigilantes debieron ofrecer pelea para lograr apresar a los revoltosos: 40 se habían fugado, 10 o 12 recibieron formidables palizas, 37 fueron reducidos a prisión encerrándolos en una sala bien guardada por cuatro vigilantes. ${ }^{26}$ Los ecos del motín, plasmados por los cronistas en los principales diarios porteños, remarcaron la efímera pero violenta revuelta identificada con los miembros del Batallón y "sus fusiles

25 Nota publicada en El Diario presentada con el título de "En el asilo de Huérfanos. La sublevación de anoche. Todos los detalles. Las causas, Moral del suceso". No aparece consignada la fecha pero por los datos debió ser publicada al día siguiente, el 19 de diciembre. Los otros medios gráficos titulaban: La Prensa, "Sublevación de asilados. Tumulto en un asilo", el diario El Pueblo, "Policía. En el asilo de huérfanos. La sublevación de anoche. Fuga de asilados". AGN, FDSB, Sala VII, Recortes Diarios.

26 AGN, FDSB, Sala VII, Recortes Diarios. 
rémington y bayonetas". ${ }^{27}$ No resulta extraño el rol de los medios gráficos porque en esos primeros años del siglo XX se sucedieron distintas polémicas en torno a los "malos tratos" recibidos por los asilados o por la administración de los fondos enviados desde el Estado a la Sociedad de Beneficencia.

Al día siguiente, los reporteros de los principales diarios (Tribuna, La Prensa y El Diario) se agolparon en las puertas del Asilo para ser recibidos por el vicerrector, recorrer las instalaciones y lograr conversar con los protagonistas. En esas líneas se ve plasmado el intento de recrear el clima previo, con sus tensiones y enfrentamientos, y de recopilar los testimonios de lo sucedido.

Los rumores que circularon durante todo el mes de diciembre sobre una futura reorganización institucional, que implicaba reformas y expulsiones, alertaron a los jóvenes de más de 14 años próximos al momento del egreso. Algunos trabajaban dentro del asilo en las tareas domésticas y en la producción de los talleres, otros desarrollaban sus actividades educativas o laborales en la vecindad. Así, la responsabilidad del motín recayó en los asilados mayores, quienes hicieron clamar su furia por las sospechas crecientes del cambio en las autoridades, la separación del padre Bernabé y su reemplazo por Gabriel Desbarats, y la eliminación de ciertos talleres.

La vinculación de los "cabecillas" con el Batallón Maipú, con los circuitos de trabajo y con los estudiantes "normalistas", promovió una serie de diagnósticos críticos sobre la formación laboral y la asistencia administrada por la Sociedad de Beneficencia con fondos del Estado. Desde la mirada del corresponsal de El Diario "el inaudito suceso de anoche en el Asilo de Huérfanos es reflejo de una realidad largamente denunciada", que no hace otra cosa más que poner en evidencia los "vicios orgánicos de las instituciones de beneficencia". ${ }^{28}$ A pesar de esta opinión crítica sobre la administración asilar, resaltaba en elogios "las virtudes y el saber" del padre Pedernera, quien era sin duda de lo mejor que podría señalarse al frente de estos establecimientos.

En este sentido, el redactor insistía en suponer que esa "especie de crueldad quirúrgica”, que la beneficencia oficial estaba acostumbrada a aplicar, fue el

27 La Nación calificaba en su encabezamiento, el 18 de diciembre de 1902, "En el Asilo de Huérfanos. Sublevación y evasión. El batallón Maipo en armas. Fuga de 35 menores. Intervención de la autoridad policial”. AGN, FDSB, Sala VII, Recortes Diarios.

28 El Diario, 18 de septiembre de 1902. AGN, FDSB, Sala VII, Recortes Diarios. 
trasfondo real del malestar entre los internos. ${ }^{29}$ Es más, en estos sitios no había régimen preciso, ni sistema definido, ni propósito claro: se recibía a los niños "que llenan las exigencias de un reglamento y una vez adentro se les enseña ejercicios militares, algún oficio manual sin consultar para nada sus aptitudes y ni sus gustos”.

Desde esta perspectiva, los cronistas del diario asemejaban sus postulados a las pretensiones de algunos profesionales y defensores de menores que exigían la promoción de carreras y oficios útiles, necesarios para el desarrollo económico del país. Por eso interpelaban a la Sociedad: ¿para qué enviaba a estudiar en las escuelas normales cuando el número de maestros y profesores "excede en mucho a las necesidades presentes y futuras de la instrucción nacional”? O bien se preguntaban qué finalidad tenía el trabajo realizado en los talleres por los menores "para compensar los beneficios que reciben del establecimiento o iban más bien a adquirir hábitos de trabajo y un oficio que les permita mañana vivir con honradez e independencia”. ${ }^{30}$

Para el cronista, la dirección priorizaba la producción interna de los objetos utilizados diariamente, sin ocuparse demasiado en la profundización del aprendizaje técnico ni mucho menos en asegurar algún tipo de retribución: "desde el momento mismo en que el niño comienza a trabajar debe también recibir un sueldo, pequeño, tan pequeño como se quiera, pero debe recibirlo”. Justamente ahí encontraba la explicación del descontento: "esos muchachos, después de cinco o seis años de trabajar en la casa, se encuentran con que no pueden dejarla porque no tienen en qué caerse muertos”. Debiéndose quedar allí hasta los 17, 18 y hasta 21 años, "en condiciones precarias para ellos y para la institución peligrosas, porque no hay orden que cumpla ni autoridad que les imponga nada”. ${ }^{31}$

La postura de la prensa reprobaba abiertamente el modelo asilar, las formas de organizar el trabajo y la utilización de los fondos públicos, que ponían en evidencia la falta de un "plan regular y científico" para transformar la beneficencia en algo útil y eficaz. ${ }^{32}$

29 Para el periodista el motín evidenciaba un grave problema social que era preciso resolver: todo el organismo de la Sociedad de Beneficencia tiene que ser sometido a un proceso severo y detallado de revisión y reforma, porque no puede ser absolutamente el de las damas, a quienes no es posible exigir pericias profesionales de alta contabilidad. El Diario. AGN, FDSB, Sala VII, Recortes Diarios.

30 AGN, FDSB, Sala VII, Recortes Diarios.

31 Ibídem.

32 La Nación, 20 de diciembre de 1902. AGN, FDSB, Sala VII, Recortes Diarios. 
En tanto, desde el informe instruido por Gabriel Desbarats, vicerrector interino, se trató de probar la existencia de un clima tenso entre los jóvenes y los niños, arengados por Pedernera, contra las autoridades. Durante el mes de diciembre se vieron en algunos grupos "malos síntomas contra la disciplina y hasta amenazas a empleados". ${ }^{33}$ Por esta razón, entre los días 16 y 17 fueron expulsados seis niños de malos antecedentes. A pesar de esta sanción, "la mala atmósfera" continuó presente en el lugar. El mismo martes (haciendo referencia al día del motín), 16 niños salieron furtivamente de la casa del Presbítero E. Pedernera, de donde se retiraron muy exaltados.

En esta descripción, el motín fue producto de las acciones violentas y conspirativas de Pedernera y sus "muchachos aliados", quienes armados con palos rompían los vidrios de puertas y ventanas a los gritos de " $i$ Viva la anarquía! ¡Viva Pedernera! ¡Muera el vicerrector!”. A partir de las confesiones de algunos internos, mediadas por el temor de futuras represalias o expulsiones, se fue configurando un relato que denunciaba la participación del antiguo rector, de los miembros del Batallón, de familiares y conocidos ajenos al asilo, quienes ingresaron al día siguiente del motín por la zona de ingreso a los talleres, para intimidar a los maestros y empleados. ${ }^{34}$

Desde la mirada institucional se presentó al motín como un hecho que puso en jaque el orden y la disciplina interna y que evidenciaba, también, la intromisión de actores ajenos a la institución. Esta versión de mostrar al asilo como un espacio atravesado por rebeliones internas y confabulaciones externas está ligada a las propuestas de reorganización, las cuales apuntaron, justamente, a controlar y limitar la dinámica asilar con la comunidad barrial.

Otra cuestión fundamental que ha sido registrada en las crónicas periodísticas y en el sumario es la voz de los “menores". En calidad de testigos o protagonistas, han expresado sus opiniones, mediadas y tuteladas por los adultos, sobre las causas de la protesta. Para la prensa, el diálogo con los

33 AGN, FDSB, Sala VII, Asilo de Huérfanos 1901-1909, legajo 93, ff. 140-143.

34 En el caso del alumno Ceferino Jiménez, en sus primeras confesiones dijo "que el señor Dardo Gómez, jefe del batallón, con algunos más (refiriéndose a los menores) fueron a la ropería a esconderse para huir de la policía. Durante su segundo interrogatorio afirmó "que obraban por insinuación de otra persona a quien tenían que seguir”; éste era el señor Gómez, hermano de Dardo Gómez, uno de los principales promotores. Este sujeto ingresó al día siguiente del motín al asilo por la zona de ingreso a los talleres, una vez allí mandó a llamar al maestro de sastrería Luis Rumussi para intimidarlo con amenazas y obligarlo a declarar que Dardo se había mantenido ajeno a todo lo ocurrido, ya que se encontraba en la ropería durante el alboroto. AGN, FDSB, Sala VII, Asilo de Huérfanos 1901-1909, legajo 93, ff. 140-143. 
chicos estaba prohibido por orden de los celadores. A pesar de la restricción, los periodistas pudieron burlar a la vigilancia, recorrieron las instalaciones del establecimiento y obtuvieron algunas declaraciones. El registro de esos encuentros daba muestra de una estructurada rutina asilar que continuó con sus labores y obligaciones domésticas y productivas después del estallido. ${ }^{35}$

En un momento pudieron estar frente a frente con los acusados que estaban apartados en un salón. Así, los enviados del diario se presentaron ante los chicos, comenzaron a conversar y a pedirles datos sobre lo sucedido en la noche. Por su parte, ellos se presentaron ante los periodistas: "vea aquí estamos nosotros que nos llamamos el señor Luna, este otro Giménez Gómez y un servidor Salvador" ${ }^{36}$.

El joven que se presentó ante los visitantes, como un par adulto, antes de relatar los acontecimientos ofreció una descripción de la situación por la que atravesaban él y sus compañeros: "desde hace cinco años estamos en el asilo estudiando y conduciéndonos siempre con corrección”. Los tres habían tenido que dejar la carrera de "profesor en la Escuela Normal" porque de pronto sin causa justificada se los expulsaba "a la calle, solos, sin recursos de ningún género, se les cortaba la carrera todo con el pretexto de cumplir 18 años". ${ }^{37}$ Bajo el reglamento del asilo o con el amparo del defensor, esa edad era considerada la instancia de egreso, por la cual los jóvenes tenían que abandonar el lugar. La mayoría de edad, establecida por el Código Civil, era la entrada al mundo adulto, pero para los "menores" también significaba el fin de la tutela.

En el diálogo mantenido con los reporteros, las palabras de los chicos expresaron ese reclamo de asistencia o acompañamiento por parte de las autoridades: "si la Sociedad no quiere costearnos la educación y darnos una carrera para que mañana podamos ser elementos útiles a la sociedad, que se

35 En su recorrido, los periodistas se encuentran con un "muchachote" con la cabeza vendada. A quien le preguntaron si era consecuencia de lo de anoche. El joven le responde: No señor, trabajando en el taller de niquelado y plateado, una polea desprendida me rajó la cabeza. Ahora voy en camino al Hospital Español. Con esta afirmación el joven ponía de manifiesto que los procesos de trabajo y producción en los talleres no habían sido interrumpidos. Nota publicada en Tribuna con el título "En el Asilo de Huérfanos. Sublevación del Batallón Maipo. Una visita al establecimiento. Medidas que se imponen”. 19 de diciembre de 1902. AGN, FDSB, Sala VII, Recortes Diarios.

36 Nota publicada en Tribuna con el título de "En el Asilo de Huérfanos. Sublevación del Batallón Maipo. Una visita al establecimiento. Medidas que se imponen”. 19 de diciembre de 1902. AGN, FDSB, Sala VII, Recortes diarios.

37 AGN, FDSB, Sala VII, Recortes Diarios. 
nos avise con tiempo, un mes antes, por ejemplo, para que cada uno pueda buscarse una colocación cualquiera”.

Según los dichos de los muchachos, se encontraban en calidad de presos dentro de la institución, amenazados de ser detenidos por la policía por su vinculación con la "sublevación”. Frente a este panorama, reafirmaban su inocencia y postulaban sus reclamos: "estamos dispuestos a no abandonar esta casa hasta tanto encontremos un empleo que nos permita vivir, porque hay que tener en cuenta que de aquí se nos larga con las manos vacías, sin medios". ${ }^{38}$ Para ellos, el hecho de tener 18 años y ser obligados a dejar la institución no suponía el final de sus experiencias laborales y educativas. Por eso, no dudaron en reclamar a la Sociedad de Beneficencia que los acompañara en ese tránsito hacia la vida afuera del asilo.

Para muchos jóvenes pobres, varones y mujeres, la medida de tutela fue la entrada a un extenso circuito laboral y de aprendizaje que les posibilitaba el pago del peculio (dinero en parte recibido y el resto depositado para su egreso), y la obtención de influencias y contactos para forjarse algún oficio o carrera. Ese contrato no podía ser incumplido intempestivamente porque estos jóvenes esperaban, justamente, que la finalización de su experiencia en el asilo les posibilitara cierta seguridad laboral.

Por parte de las autoridades el sumario dejó constancia de los promotores del desorden: Dardo Gómez, jefe del Batallón, de 17 años de edad. Ceferino Giménez, normalista presidente de la Comisión Patriótica, de 18 años. Pedro Salvador, normalista, de 17 años. Reinaldo Casco de 17 años, de la escuela de pilotos. Eduardo Pomperan de 16 años, fotógrafo. De los otros dos acusados no se logra entender bien sus nombres pero el primero, de 18 años, era zapatero, y el otro, de 16, era estudiante. Según los datos recogidos en el informe, el señor Gómez, aunque de escasa inteligencia, fue presentado como el más activo promotor del desorden instando bajo amenaza la participación de la mayoría de los 43 amotinados.

La sanción de las autoridades determinó la detención de siete menores por la policía; otros 41 estuvieron custodiados en un salón del asilo. Luego se decidió la expulsión inmediata de todos los acusados de participar y de todos los mayores de 18 años del asilo, se suprimieron los llamados normalistas que constantemente salían del establecimiento a cursar en las escuelas normales, todos ellos debieron salir del asilo por participar del desorden o por estar

38 Ibídem. 
fuera del reglamento por su mayoría de edad. ${ }^{39}$ Solo 5 de los 41 niños eran expósitos y fueron presentados al juez competente para que dispusiera de ellos, en cambio, la mayoría había cumplido sobradamente los años de edad fijada en el reglamento (10 años). ${ }^{40}$

El 22 de diciembre de 1902 se realizó el listado de los huérfanos mayores de 18 años que se habían movilizado durante el motín: sobre ellos se decidió el abandono definitivo del asilo manteniendo sus relaciones laborales en los talleres. De esta manera, se los castigaba por su condición de tutelados rebeldes pero se confirmaba su necesaria permanencia en la vida productiva del establecimiento.

Además, 9 niños expósitos que por su conducta incorregible no podían permanecer en el Asilo fueron puestos a disposición del Juez de menores. Se transcribieron sus nombres en una lista, aclarando que el primero de ellos (Ramón Saenz Peña, de 14 años) tenía un pedido de colocación tramitado en la Dirección del Asilo de Huérfanos por el comerciante señor Francisco Partieri (a cuyo efecto se remitía todas las certificaciones pertinentes), y los dos precedentes (Luciano Guiraldes y Enrique García, ambos de 13) habían sido reclamados por el jefe del Regimiento de infantería para incorporarlos como aprendices de músico en la banda del batallón. ${ }^{41}$ De esta manera, las secuelas del motín se concentraron en contener y limitar los trabajos que conectaban a los asilados con la comunidad, y a reforzar las actividades laborales vinculadas al sostenimiento de la organización interna de los establecimientos de la Sociedad de Beneficencia.

\section{Consecuencias del motín: reestructuración del trabajo tutelado}

El estallido del motín tuvo una notable repercusión en la opinión pública de la ciudad y generó un rápido reajuste de las reglas, de la formación, y del trabajo, el cual siguió siendo el eje decisivo de las rutinas cotidianas y de la economía de las instituciones.

El levantamiento implicó la remoción de las autoridades (tal es el caso del padre Pedernera), la expulsión de internos o su reubicación en nuevos

39 Informe de Rómulo Ayerza, miembro de la Comisión para reorganizar el Asilo, que es adjuntado al finalizar el escrito de Gabriel Desbarats. AGN, FDSB, Sala VII, Asilo de Huérfanos 1901-1909, legajo 93, ff. 145-148.

40 AGN, FDSB, Sala VII, Asilo de Huérfanos 1901-1909, legajo 93.

${ }_{41}$ Decisión tomada por las autoridades en base a los pedidos de las inspectoras. AGN, FDSB, Sala VII, Asilo de Huérfanos 1901-1909, legajo 93. 
destinos laborales o educativos fuera del establecimiento asilar. Pero, a partir de ese episodio, la comisión directiva y las empleadas de la Sociedad ejecutaron una profunda transformación de las reglas y de las dinámicas cotidianas del establecimiento. Esto ocasionó una severa reorganización de la enseñanza y del trabajo: se cancelaron los contratos de todos los profesores hasta nuevo aviso, se suspendieron los batallones, y se suprimió al oficial del Ejército Nacional que con sueldo mensual dictaba las enseñanzas teóricoprácticas.

Por otro lado, se consideró mejorar el desarrollo de la educación "limitando" el estudio de los niños a las materias de los primeros grados, debiendo ocupar las clases "cuando más la tercera parte de las horas de taller". Los internos mayores de 18 años debían abandonar el lugar por cuestiones reglamentarias, pero muchos de ellos fueron inmediatamente contratados para ocuparse en los talleres. Las inspectoras decidieron cerrar los talleres de galvanoplastía, fotografía y colocación de campanillas y teléfonos: así desaparecían "dos talleres que no tenían importancia alguna y que carecen de discípulos, y un tercero que por ocupar a los niños en trabajos fuera de la casa a todas luces resultaba inconveniente". ${ }^{29}$ Los talleres que continuaban su dictado eran los de ajuste y herrería, carpintería, hojalatería, plomería, canastería, imprenta y encuadernación, sastrería y zapatería. Todos los oficios y actividades desarrolladas debían estar adaptados a las edades de los internos, manteniéndose una división rigurosa de las clases, talleres, dormitorios y recursos según los años.

Respecto a las actividades productivas, las autoridades decidieron la prohibición total de las salidas de los niños para realizar trabajos por cuenta de particulares. Desde ese momento, los trabajos se ejecutaban exclusivamente dentro de la "casa". No solo no se podía salir al exterior, es decir a la vecindad y a la ciudad en búsqueda de oportunidades laborales, sino que también se reducían los contactos con conocidos y parientes: "la incomunicación de los asilados con el público, ha quedado de hecho establecida, pues no existen ya ni normalistas, ni obreros que trabajen fuera y se ha suprimido así una de las importantes causas de indisciplina”. Al año siguiente, en 1903, se redactó un nuevo reglamento que estableció un reordenamiento administrativo y una profunda demarcación de las actividades cotidianas del asilo; desde el trabajo, hasta la educación, el tiempo de recreación y el contacto con sus familias.

42 AGN, FDSB, Sala VII, Asilo de Huérfanos 1901-1909, legajo 93, ff. 148 al 150. 
El motín puso en escena el importante componente gestual y sensorial de un grupo de jóvenes acostumbrados a vivir en los asilos y a circular por las redes educativas y laborales que se les presentaban en el marco de una relación tutelar, la cual podía estar determinada por la ausencia de sus padres o por la pobreza "material y moral" de sus familias. Sin lugar a dudas, estos "muchachos" habrán tenido que sostener numerosas micro batallas en su trayectoria institucional. En el día a día desafiaban a autoridades (directores, defensores de menores), a celadores, a patrones e incluso a otros internos, confrontaciones habituales que en los legajos han sido plasmadas como peleas, robos, fugas o altercados.

¿Por qué en diciembre de 1902 los cuerpos y los deseos de estos internos provocaron la irrupción de una protesta violenta y colectiva hacia los poderes y las normas del asilo? Probablemente, ese año coincidió con desavenencias entre las autoridades en torno al funcionamiento de los talleres y al uso del trabajo asilado. En ese entonces, el padre Bernabé Pedernera llevaba más de diez años de director y su visión sobre las actividades laborales se estaba alejando de los ideales de las socias de la Comisión Directiva. En ese clima tenso de disputas entre los adultos del asilo, los jóvenes se lanzaron a la lucha y entregaron su bien más preciado: sus cuerpos sobre los cuales se inscriben los avatares de los días, por lo general producidos por las exigencias sociales y políticas. ${ }^{43} \mathrm{Su}$ energía corporal tomó las instalaciones, se apropió de las armas del Batallón Maipú y llevó a cabo destrozos de vidrios y puertas.

Los nombres de los promotores de la lucha, como se ha destacado, formaban parte del Batallón, de los talleres y del grupo de los normalistas. Es decir, muchachos que todavía eran alojados en el asilo pero que durante gran parte del día se encontraban fuera de él estudiando o trabajando. Las probables expulsiones, que se rumoreaban en los días previos, podían dejar a estos en chicos en una compleja situación de abandono, pero esta vez no de parte de sus parientes sino de los responsables de ejercer la tutela pública.

Lo interesante del motín es que se enfrentaron de cara al poder sin intermediarios. No se acercaron a las oficinas de los defensores ni tampoco escribieron cartas a las señoras de la Sociedad clamando por su futuro. Algo de lo vivido resultó intolerable: el alejamiento del director Pedernera, quien por más de diez años manejó el establecimiento y coordinó sus actividades. O quizás simplemente el sentimiento de perder todo lo que conocían y habían tenido hasta ese momento.

43 Arlette Farge, Efusión y tormento. El relato de los cuerpos. Historia del pueblo en el siglo XVIII (Buenos Aires: Katz, 2008), 16. 
Según las crónicas periodísticas y los informes sumariales podemos saber que los principales líderes, tales como Dardo Gómez, fueron expulsados. Pero en el listado que las inspectoras adjuntaron con fecha del 22 de diciembre de 1902 se aclaraba que la mayoría de los que tenían padres fueron entregados a sus familias, y varios de los que estaban en condición de expósitos fueron reubicados en dependencias militares o en destinos laborales que ya habían sido establecidos antes de la rebelión. Por ello, se podría decir que lo que perdieron muchos de ellos fue la permanencia en el asilo como alumnos o internos, pero lograron mantener su vinculación con la Sociedad en calidad de trabajadores.

Más allá de las disputas personales que podrían haber existido entre los adultos y los "menores" del asilo, la mayor contienda se desplegó en torno a las formas de sobrevivencia, y concretamente en torno al trabajo con sus múltiples usos y sentidos. Por ejemplo, las secciones que fueron eliminadas a partir de diciembre de 1902 eran galvanoplastía, fotografía, y colocación de campanillas y teléfonos. Desde la visión de las inspectoras y socias de la Comisión Directiva, estos oficios tenían poca rentabilidad o bien implicaban que los encargos de trabajo se hicieran en casas y negocios de la vecindad.

Es relevante pensar si estas desavenencias en torno a la utilidad de los trabajos de los menores nos ubican frente a un complejo campo de tensión, donde se entrecruzan prejuicios de clase y nuevas dinámicas productivas. Es decir, si estos adultos que administraban los talleres y las redes de colocación estaban enfocados en reproducir ciertas trayectorias laborales entre los niños y jóvenes pobres, o bien preferían generar saberes y oficios con alta demanda en los nuevos mercados de trabajo, que se abrían al compás de la modernización y crecimiento de la economía.

Estas controversias alrededor de las múltiples formas del trabajo infantil y juvenil de las clases bajas nos ubican en un complejo entramado, que refleja tanto las profundas desigualdades económicas como las prácticas asentadas y naturalizadas de una comunidad acostumbrada a ver y a utilizar la fuerza de trabajo de los hijos e hijas de las familias populares. En esta constante, y a veces invisibilizada, circulación de niñas y niños trabajadores se manifiestan valores e intereses opuestos. ${ }^{44}$

44 En esta investigación focalizada en Estados Unidos, se pueden apreciar los conflictos en torno a los acuerdos y contratos realizados por la Cortes Juveniles y las familias populares. Mientras las autoridades colocaban a los niños y jóvenes en trabajos de escasa rentabilidad y con gran participación de esclavos, los padres preferían ubicar a sus hijos como aprendices de oficios con gran reputación y libres del trabajo esclavo. Stephen Whitman, "Orphans in city and 
El descontento que resonó en el asilo y traspasó sus paredes, haciendo eco en la comunidad y en la prensa porteña, puso en evidencia los reclamos y las apreciaciones de pibes y jóvenes humildes. Ellos exigieron la continuidad de sus estudios y de sus trabajos, los cuales no podían terminar de forma intempestiva como pretendían ciertas autoridades; reconocían en la medida tutelar un compromiso de protección y previsión para el tránsito a su vida adulta. El ingreso al asilo debía implicar no solo la provisión de ropa, techo y alimento, sino que, también, debía proveer conocimientos, herramientas y contactos para insertarse en las trayectorias laborales de la ciudad.

Quizás la figura de la tutela ha estado, en la mayoría de los casos, asociada a las interpretaciones y acciones desplegadas desde arriba (autoridades) hacia el llano (familias y barriadas populares de la ciudad). Pero en esta ocasión, son los propios internos, quienes reestructuran y proclaman los valores y objetivos de la función del patronato público sobre sus experiencias de vida. Con su lucha, ellos invirtieron esa relación de subordinación (o de minoridad) que existía por parte de las autoridades, y defendieron sus derechos a ser protegidos y amparados en su pasaje al mundo adulto por medio de una segura colocación laboral, tanto en la Sociedad de Beneficencia o en las oportunidades de trabajo que brindaba la ciudad.

El desafío que nos presenta este motín es poder pensar ciertas trayectorias de trabajo de las infancias y juventudes tuteladas, más allá de los sentidos y usos clasistas-estigmatizantes que se dieron en la época. De esta manera, se podrá avanzar en un análisis que integre la cotidianidad del asilo y la centralidad del trabajo de los "menores" con problemas centrales de la historiografía de los trabajadores en nuestro país, tales como las trayectorias de las familias populares, las condiciones materiales de vida, los contextos de conflictividad obrera, y los ciclos productivos abiertos por el mercado de trabajo.

countryside in nineteenth-century Maryland", en Children bound to labor. The pauper apprentice system in early America, ed. Ruth Wallis Herndon-John E. Murray (Nueva York: Cornell University Press, 2009), 52-70. 
Title: Mutiny at the Orphanage. Reflections on the Meanings and Uses of Work. Buenos Aires, 1902

Abstract: The article aims to analyze the riot unleashed in the Orphanage (Asilo de Huérfanos) of Buenos Aires, on December 1902. The Charitable Society (Sociedad de Beneficencia), administrator of the institution, gathered at that time the journalistic articles and summaries of the investigations opened by the authorities. Drawing upon this collection of documents, an attempt will be made to reconstruct that fleeting episode of struggle, focusing primarily on the analysis of the labour experiences both inside and outside the asylum, and the expectations and antagonistic perceptions regarding the uses and meanings of the work of the children and young of the lower classes.

Keywords: childhood and youth, poverty, work, guardianship

Título: O Motim do Orfanato. Reflexões sobre os significados e usos do trabalho. Cidade de Buenos Aires, 1902

Resumo: $\mathrm{O}$ artigo tem como objetivo analisar o motim desencadeado no Orfanato (Asilo de Huérfanos) da cidade de Buenos Aires, em dezembro de 1902. A Sociedad de Beneficencia, administradora do referido estabelecimento, reunia na época os artigos jornalísticos e resumos das investigações abertas pelas autoridades. Através deste conjunto documental, procurar-se-á reconstruir aquele fugaz episódio de luta, tendo como eixo central a análise das experiências laborais dentro e fora do orfanato e as expectativas e percepções antagónicas quanto aos usos e significados do trabalho das crianças e jovens das classes baixas.

Palavras-chave: infância e juventude, pobreza, trabalho, tutela 